\title{
Healthcare maintenance in elderly patients with inflammatory bowel disease
}

\author{
Manish P. Shrestha ${ }^{a}$, Joannie Ruel ${ }^{b}$, Sasha Taleban ${ }^{c, d}$ \\ University of Arizona College of Medicine, Tucson, Arizona; University of Sherbrooke, Sherbrooke, Quebec, Canada; \\ University of Arizona Center of Aging, USA
}

\begin{abstract}
The increasing number of older patients (age $\geq 60$ years) with inflammatory bowel disease (IBD) highlights the importance of healthcare maintenance in this vulnerable population. Older IBD patients are more susceptible and have higher rates of many disease- and treatment-related adverse effects. Compared to younger IBD patients, older patients are at increased risk for infection, malignancy, bone disease, eye disease, malnutrition and thrombotic complications. Preventive strategies in the elderly differ from those in younger adults and are imperative. Changes to the immune system with aging can decrease the efficacy of vaccinations. Cancer screening guidelines in older IBD patients have to account for unique considerations, such as life expectancy, functional performance status, multimorbidity, financial status, and patient desires. Additionally, providers need to be vigilant in screening for osteoporosis, ocular disease, depression, and adverse events arising from polypharmacy.
\end{abstract}

Keywords Age, elderly, healthcare maintenance, inflammatory bowel disease

Ann Gastroenterol 2017; 30 (3): 1-14

\section{Introduction}

Healthcare maintenance strategies in older adults decrease influenza-related complications, colorectal cancer (CRC), and cardiovascular events [1-3]. Despite the clear benefits of health maintenance, less than $50 \%$ of older adults receive recommended vaccinations and cancer screenings [4]. In inflammatory bowel disease (IBD), older patients may be more susceptible to preventable events. However, IBD patients are less likely than the general population to receive preventive services [5]. The reasons for this disparity are unclear, but possible explanations include providers focusing more on IBD treatment than on preventive services, low patient priority for such services,

${ }^{\mathrm{a} D e p a r t m e n t ~ o f ~ M e d i c i n e, ~ U n i v e r s i t y ~ o f ~ A r i z o n a ~ C o l l e g e ~ o f ~ M e d i c i n e, ~}$ Tucson, Arizona (Manish P. Shrestha); ${ }^{\mathrm{b} D}$ Division of Gastroenterology, University of Sherbrooke, Sherbrooke, Quebec, Canada (Joannie Ruel); 'Division of Gastroenterology, University of Arizona College of Medicine, Tucson, Arizona (Sasha Taleban); ${ }^{\mathrm{d} D e p a r t m e n t ~ o f ~}$ Medicine, University of Arizona Center of Aging, Tucson, Arizona (Sasha Taleban), USA

Conflict of Interest: Joannie Ruel: speaker and consultant for AbbVie, Janssen, Takeda, Shire, Ferring

Correspondence to: Manish P. Shrestha, MD, $1501 \mathrm{~N}$ Campbell Ave, Tucson, AZ 85724, USA, Tel.: +1 520626 5797, Fax: +1 520626 5721, e-mail: manish9s@hotmail.com

Received 29 December 2017; accepted 20 January 2016; published online 17 February 2017

DOI: https://doi.org/10.20524/aog.2017.0130 provider time constraints and reimbursement issues, lack of a primary care physician (PCP) for many IBD patients, ambiguity in the medical community as to whether a gastroenterologist or a PCP should provide such services, and lack of physician comfort $[5,6]$. Moreover, advancing age is associated with lower rates of preventive services, partly as a result of the physician's and patient's lack of expectation of benefits from these services [7].

Several strategies have been suggested for improving the rates of preventive services for IBD patients. These include separate preventive-care visits, use of quality improvement initiatives, use of electronic medical record tools to alert patients or providers of preventive services, and greater involvement of gastroenterologists in delivering such services. Improved collaboration between PCPs and gastroenterologists can improve the delivery of preventive services for IBD patients [8].

With an aging population and increasing prevalence of IBD [9], the identification and application of age-related health maintenance strategies is crucial. In this review, we discuss some of the most important healthcare maintenance issues for older IBD patients, including vaccinations, cancer screening, bone health, mental health, nutritional status, smoking cessation, prevention of venous thromboembolism, eye health, oral health and polypharmacy.

\section{Vaccinations}

Infections account for significant morbidity and mortality in older IBD patients, partly because of the age-related decline 
in immune system function (i.e. immunosenescence) $[10,11]$. IBD treatment often requires the use of immunosuppressive therapy, which further increases the risk of infections [11]. In a study based on a national inpatient database in the US, IBD patients $>65$ years old had an increased risk of developing pneumonia (odds ratio [OR] 4.01, 95\% CI 3.33-4.82) or sepsis (OR 2.30, 95\% CI 1.90-2.79), and a 20\% increased risk for infection-related hospitalizations [12]. In another study based on data from IBD patients at 16 Italian tertiary referral centers, IBD patients $>65$ years old on tumor necrosis factor (TNF) inhibitors had a higher rate of severe infections and mortality than control patients $<65$ years old $(11 \%$ vs. $2.6 \%$ severe infections, $\mathrm{P}=.004 ; 10 \%$ vs. $1 \%$ mortality, $\mathrm{P}<0.0006$ ) [11].

Vaccination recommendations are similar for elderly patients with and without IBD, though there are some exceptions regarding live vaccines [13-15]. Patients with IBD generally mount appropriate responses to vaccinations, although patients $\geq 65$ years old and patients on biologics and/or immunemodifying agents may have a decreased immune response to vaccinations [16-21]. Therefore, particularly in the elderly, obtaining antibody titers and appropriate vaccinations before the initiation of immunosuppressive therapy may be especially important. Some authors have suggested using higher initial vaccination doses, checking post-vaccination titers, administering booster doses, and using conjugated vaccines, when appropriate $[15,16,22,23]$. Further studies are needed to assess the efficacy and cost-effectiveness of such vaccination strategies.

\section{Live vaccines}

Live vaccines are typically avoided in patients using glucocorticoids (prednisone $>20 \mathrm{mg}$ /day equivalent for $\geq 2$ weeks or $<3$ months after stopping), immune-modifying agents (6-mercaptopurine [6-MP]/azathioprine/methotrexate, ongoing use or within 3 months of discontinuation), or biologics (ongoing use or within 3 months of discontinuation) and patients with severe protein calorie malnutrition [14]. Live vaccines could be administered 3-4 weeks before starting immune-modifying agents/biologics and 3 months after the last dose $[22,24]$. The latter delay may be reduced to 1 month in the case of corticosteroid use alone [25].

\section{Measles, mumps, and rubella (MMR)}

Adults born before 1957 are generally considered immune to measles and mumps. The Advisory Committee on Immunization Practices makes no specific MMR vaccination recommendations for adults aged 60 or older, except for healthcare personnel. For unvaccinated healthcare personnel lacking immunity to any of these viruses, vaccination should be considered ( 2 doses for measles and mumps, 1 dose for rubella) [26]. Some authors suggest checking antibody titers in older IBD patients with an unknown vaccination history. In immunocompetent patients who lack immunity to any of these viruses, the vaccine should be administered [13].

\section{Varicella}

The absolute risk of primary varicella infection in older IBD patients is unknown. Cullen et al identified 20 reported cases of primary varicella infection in IBD patients, with 5 deaths [27]. The risk of infection increased with immunosuppressive therapy, particularly with corticosteroids and combination immunosuppressive therapy [27].

Although adults born in the US before 1980 are considered immune to varicella, with the exception of pregnant women and healthcare personnel, IBD patients should be tested for varicella zoster virus antibody titers if there is uncertainty about their history of infection or vaccination [13,28]. A twodose varicella vaccine, with at least 4 weeks between doses, is recommended for seronegative, immunocompetent adults. In seronegative patients on immunosuppressive therapy, varicella vaccine may be administered 3-6 months following cessation of all immunosuppressive therapy [28].

\section{Herpes zoster}

Old age is a known risk factor for herpes zoster infection and post-herpetic neuralgia [25]. The risk is increased among patients with IBD, especially those on immunosuppressive therapy [29]. In a retrospective cohort study based on a general practice database from the United Kingdom, the incidence of zoster infection increased with advancing age, with the highest rates among IBD patients $\geq 65$ years old (1291 per 100,000 person-years in patients with Crohn's disease [CD] and 1143 per 100,000 person-years in patients with ulcerative colitis [UC]). The incidence of zoster was significantly higher for both CD and UC patients compared with their age- and sex-matched controls [29].

A one-dose zoster vaccine is recommended for immunocompetent individuals $\geq 60$ years old [25]. Unlike with other live vaccines, it is not necessary to check the varicella antibody titer prior to vaccination [22]. Although live vaccines are generally avoided in immunosuppressed patients, the use of the live zoster vaccine in IBD patients is controversial. Patients on short-term corticosteroid therapy ( $<14$ days), or long-term alternate day treatment with low to moderate doses of shortacting systemic corticosteroids, or low doses of methotrexate $(<0.4 \mathrm{mg} / \mathrm{kg} /$ week $)$, azathioprine $(<3.0 \mathrm{mg} / \mathrm{kg} /$ day $)$, or $6-\mathrm{MP} \quad(<1.5 \mathrm{mg} / \mathrm{kg} /$ day $)$, are not considered sufficiently immunosuppressed and therefore can receive the vaccine [25]. Data on the safety and efficacy of zoster vaccine in patients using biologics are limited. In a retrospective cohort study among older patients ( $\geq 60$ years) with selected immunemediated diseases, including 66,751 patients with IBD, Zhang et al found that none of the 633 patients with immunemediated disease exposed to biologics at the time of zoster vaccination or within the subsequent 42 days developed herpes zoster or varicella, suggesting the possible safety of zoster vaccine in such patients [30]. Nonetheless, it is advisable to practice caution while administering zoster vaccine to patients on biologics, taking into account the immune status of the recipient on a case-by-case basis to determine the risks and benefits of vaccination. 
A two-dose inactivated adjuvant vaccine ( $\mathrm{HZ} / \mathrm{su})$ has been found to reduce the risk of herpes zoster significantly in older adults [31]. Inactivated zoster vaccine may be particularly useful in older, immunosuppressed IBD patients.

\section{Inactivated vaccines}

Inactivated vaccines can be administered safely to older IBD patients, regardless of their immune status. Although the immune system's response to such vaccines may be diminished in older patients and in patients on immunosuppressive therapy [17-21], it is still important to administer the recommended vaccines, as the majority of these patients may still develop sufficient antibodies to provide protection $[16,21,32]$.

\section{Influenza}

Over $80 \%$ of influenza-related deaths occur in the elderly and older adults have significantly higher morbidity from the infection [33]. In a cohort of about 700,000 communitydwelling older people, the influenza vaccine was associated with a $27 \%$ reduction in hospitalizations due to pneumonia or influenza and a $48 \%$ reduction in deaths [1].

A one-dose inactivated influenza vaccine is recommended annually for all elderly patients, optimally before the onset of influenza season. Live attenuated influenza vaccine should be avoided in adults over the age of 49 years and in immunosuppressed patients [26].

Vaccination strategies such as the use of high-dose influenza vaccine or administration of booster doses have been suggested [15]. High-dose inactivated influenza vaccine was found to be more effective than standard-dose influenza vaccine in a multicenter trial involving adults aged 65 years or older [34]. Although standard-dose influenza vaccine is recommended for older IBD patients, high-dose influenza vaccine may be considered, particularly if there is a concern about an inadequate immune response.

\section{Pneumococcal vaccine}

Pneumococcal pneumonia and sepsis cause significant morbidity and mortality in older adults. The rate and mortality of pneumococcal disease increase significantly at age 65 [35]. Patients with IBD are at increased risk for pneumonia [36]. In a large retrospective cohort study including 108,604 IBD patients, the overall incidence of pneumonia in IBD patients was 138/10,000 person-years, compared with 76/10,000 person-years in the nonIBD cohort (incidence rate ratio 1.82 ). IBD patients $>60$ years old had the highest incidence of pneumonia at 226/10,000 person-years. The use of immunosuppressive medications, particularly corticosteroids, was associated with an increased risk of pneumonia among IBD patients [36]. Furthermore, older IBD patients are at increased risk of pneumonia-related hospitalizations and deaths $[11,12]$. Therefore, pneumococcal vaccine is recommended for all older IBD patients, regardless of their immunosuppression status $[15,28]$.
Both 23-valent polysaccharide vaccine (PPSV23; Pneumovax) and 13-valent pneumococcal conjugate vaccine (PCV13) can be administered to adults aged 65 years or older. For all elderly patients, at least one dose of PCV13 is recommended to be included in the vaccination regimen (Table 1) [26].

\section{Tetanus, diphtheria, and pertussis}

Older adults are at increased risk for tetanus and tetanusrelated mortality, primarily because of inadequate or no vaccination. More than half of tetanus cases occur in adults $\geq 60$ years old. The rate of tetanus and mortality increase significantly at age 80 [37].

A one-time dose of Tdap with a Td booster every 10 years is recommended for all older IBD patients, regardless of immunosuppression [15]. Any patient with an unknown vaccination history should complete a primary vaccination series with the first two doses at least 4 weeks apart and the third dose 6-12 months after the second dose [26].

\section{Hepatitis A}

A two-dose vaccine followed by a booster dose 10 years later should be considered in all older IBD patients who have not been vaccinated or lack immunity to hepatitis A virus $[13,22,38]$. Hepatitis A vaccine is generally considered safe and effective in IBD patients.

\section{Hepatitis B virus (HBV)}

Cases of severe reactivation of chronic HBV infection related to anti-TNF therapy have been described in patients with Crohn's disease [39]. A three-dose hepatitis $B$ vaccine at 0 , $1-2$, and 4-6 months is recommended for all older unvaccinated IBD patients with specific risk factors (Table 1) $[15,26]$.

Older age and anti-TNF therapy are strongly associated with low response rates to hepatitis $B$ vaccination $[16,40]$. In a study of 129 IBD patients, Vida Perez et al found that nearly two thirds of the patients had a suboptimal serological response after $\mathrm{HBV}$ vaccination, with older patients showing a lower response rate than younger patients (30.91 vs. 39.91, $\mathrm{P}<0.001$ ) [40]. Another study also noted a lower response rate to $\mathrm{HBV}$ vaccination in older IBD patients (OR 0.96, $\mathrm{P}<0.001)$. In addition to older age, anti-TNF therapy was associated with a lower response rate (OR 0.39, $\mathrm{P}<0.01)$ [16]. Therefore, it is recommended to test all older IBD patients for hepatitis B serology prior to initiation of immunosuppressive therapy [13]. Post-vaccine titers should be checked 1-2 months after the last dose to determine the need for revaccination. In patients who show a suboptimal response, revaccination with twice the standard dose of hepatitis B vaccine in three or four doses should be considered. Alternatively, vaccination with a combined hepatitis A and B vaccine can be considered, as the hepatitis A component may provoke an adjuvant-like effect. These strategies seem to be effective in generating an adequate immune response in such patients [41]. 
4 M. P. Shrestha et al

Table 1 Vaccination recommendations for older patients with inflammatory bowel disease

\begin{tabular}{|c|c|c|c|c|}
\hline Type of vaccine & $\begin{array}{l}\text { Need for } \\
\text { titers before } \\
\text { vaccination }\end{array}$ & Frequency of administration & $\begin{array}{l}\text { Patient on } \\
\text { immunosuppressive } \\
\text { therapy }^{\text {a }}\end{array}$ & Comment \\
\hline \multicolumn{5}{|l|}{ Live vaccine } \\
\hline MMR & $\begin{array}{l}\text { Yes if } \\
\text { unknown } \\
\text { vaccination } \\
\text { history }\end{array}$ & $\begin{array}{l}\text { If no immunity, } \\
2 \text { doses, } 4 \text { weeks } \\
\text { apart }\end{array}$ & Contraindicated & $\begin{array}{l}\text { Immuno-suppressive therapy } \\
\text { should not be } \\
\text { started for a } \\
\text { minimum of } \\
4 \text { weeks from } \\
\text { vaccination }\end{array}$ \\
\hline Varicella & $\begin{array}{l}\text { Yes if } \\
\text { unknown } \\
\text { history of } \\
\text { vaccination or } \\
\text { infection }\end{array}$ & $\begin{array}{l}\text { If no immunity, } \\
2 \text { doses at least } 4 \\
\text { weeks apart }\end{array}$ & Contraindicated & $\begin{array}{l}\text { Immuno-suppressive therapy } \\
\text { should not be } \\
\text { started for a } \\
\text { minimum of } \\
\text { 3-4 weeks from } \\
\text { vaccination }\end{array}$ \\
\hline Zoster & No & $\begin{array}{l}1 \text { dose at age } \\
60 \text { years or older }\end{array}$ & $\begin{array}{l}\text { Consider on case-by-case } \\
\text { basis taking into account } \\
\text { the immune status of the } \\
\text { recipient }\end{array}$ & $\begin{array}{l}\text { Immuno-suppressive therapy } \\
\text { should not be } \\
\text { started for a } \\
\text { minimum of } \\
1 \text { month from } \\
\text { vaccination }\end{array}$ \\
\hline \multicolumn{5}{|l|}{ Inactivated vaccine } \\
\hline Influenza & No & 1 dose annually & $\begin{array}{l}\text { Administer only } \\
\text { inactivated vaccine. Avoid } \\
\text { live influenza vaccine }\end{array}$ & $\begin{array}{l}\text { High dose } \\
\text { inactivated influenza vaccine } \\
\text { may be considered }\end{array}$ \\
\hline Pneumococcal & No & $\begin{array}{l}1 \text { dose PCV13 } \\
\text { followed by } \\
\text { PPSV23 at least } 1 \\
\text { year after PCV13 }\end{array}$ & $\begin{array}{l}1 \text { dose PCV } 13 \text { followed by } \\
\text { PPSV } 23 \text { at least } 8 \text { weeks } \\
\text { after PCV13 }\end{array}$ & $\begin{array}{l}\text { Consider vaccination prior } \\
\text { to immunosuppressive } \\
\text { therapy to } \\
\text { improve immune } \\
\text { response }\end{array}$ \\
\hline $\begin{array}{l}\mathrm{Td} / \mathrm{Tdap} \text { (tetanus, } \\
\text { diphtheria, pertussis) }\end{array}$ & No & $\begin{array}{l}\text { If no prior } \\
\text { vaccination, } \\
3 \text { doses }(0,1,6-12 \\
\text { months). Otherwise, } 1 \text { dose } \\
\text { of Tdap followed by a booster } \\
\text { of Td every } 10 \text { years }\end{array}$ & $\begin{array}{l}\text { Same as } \\
\text { recommended regimen }\end{array}$ & \\
\hline Hepatitis A & Yes & $\begin{array}{l}2 \text { doses at } 0,6-12 \\
\text { months; booster } \\
>10 \text { years }\end{array}$ & $\begin{array}{l}\text { Same as } \\
\text { recommended regimen }\end{array}$ & $\begin{array}{l}\text { Consider vaccination prior } \\
\text { to immunosuppressive } \\
\text { therapy to improve immune } \\
\text { response }\end{array}$ \\
\hline Hepatitis B & Yes & $\begin{array}{l}3 \text { doses at } 0,1-2 \text {, } \\
4-6 \text { months for } \\
\text { patients with } \\
\text { specific risk } \\
\text { factors }^{b}\end{array}$ & $\begin{array}{l}\text { Vaccination with } \\
\text { double dose }\end{array}$ & $\begin{array}{l}\text { Check post- } \\
\text { vaccination titers after } \\
1-2 \text { months. If no response, } \\
\text { revaccinate with } \\
\text { double dose or } \\
\text { combined hepatitis } \\
\text { A and B vaccine }\end{array}$ \\
\hline Meningococcal & No & $\begin{array}{l}\text { If no prior } \\
\text { vaccination, vaccinate at-risk } \\
\text { patients with } 2 \\
\text { doses at } 0,2 \\
\text { months }^{c}\end{array}$ & $\begin{array}{l}\text { Same as } \\
\text { recommended regimen }\end{array}$ & \\
\hline
\end{tabular}

(Contd...) 
Table 1 (Continued)...

\begin{tabular}{|c|c|c|c|c|}
\hline Type of vaccine & $\begin{array}{l}\text { Need for } \\
\text { titers before } \\
\text { vaccination }\end{array}$ & Frequency of administration & $\begin{array}{l}\text { Patient on } \\
\text { immunosuppressive } \\
\text { therapy }^{\mathrm{a}}\end{array}$ & Comment \\
\hline $\begin{array}{l}\text { Haemophilus } \\
\text { influenza type b }\end{array}$ & No & $\begin{array}{l}\text { If no prior vaccination, } \\
\text { vaccinate at-risk } \\
\text { patients with } 1 \text { or } 3 \\
\text { doses }^{\text {d }}\end{array}$ & $\begin{array}{l}\text { Same as recommended } \\
\text { regimen }\end{array}$ & \\
\hline \multicolumn{5}{|c|}{ 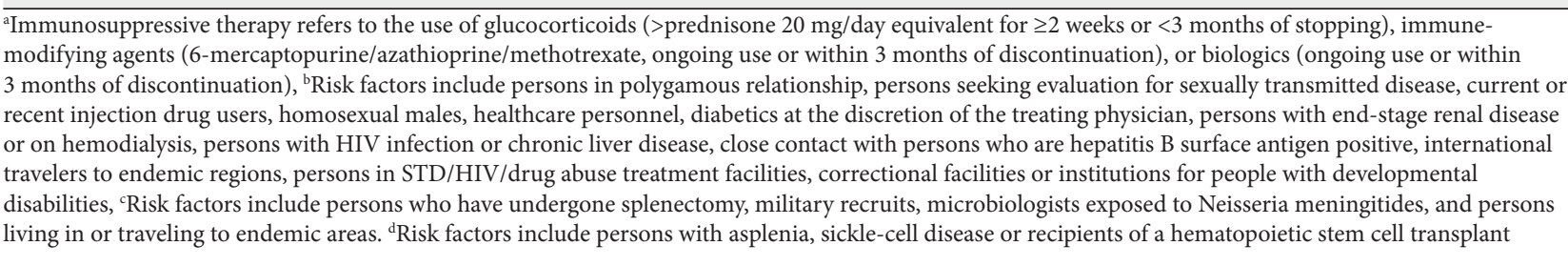 } \\
\hline
\end{tabular}

IBD patients on immunosuppressants should be vaccinated with higher doses of hepatitis B vaccine $[26,28]$. For those with an ongoing risk of exposure to $\mathrm{HBV}$, annual testing for anti-HBs antibody titers and booster doses should be considered [28].

\section{Meningococcal}

Meningococcal vaccine should be given to all at-risk older IBD patients, regardless of their immunosuppression status (Table 1) $[13,15,26]$.

\section{Haemophilus influenzae}

A one- or three-dose Haemophilus influenzae type b (Hib) vaccine is recommended for persons with specific risk factors (Table 1) [26]. A 6-year analysis of a nationwide inpatient sample found an increased risk of hospitalization with Haemophilus influenzae pneumonia in patients with IBD [42]. One quarter of these patients were older than 70 years. Therefore, Hib vaccination may be considered in elderly patients with IBD.

\section{Cancer screening}

IBD patients are at increased risk of malignancy compared with the general population [43]. In a population-based cohort study from Canada, patients with CD had a significantly greater incidence of cancer at all sites compared with the non-IBD population (incidence rate ratio 1.29). IBD patients $\geq 60$ years old had a significantly higher risk of colon cancer compared with the age- and gender-matched non-IBD cohort (incidence rate ratio 2.09) [43]. Old age is an independent risk factor for many cancers associated with IBD and its treatments [44-49]. As a result of the chronic inflammation associated with IBD, these patients are at increased risk of CRC, small intestinal adenocarcinoma (SIA), and cholangiocarcinoma (CC) [44-46]. IBD-related treatment with thiopurines is associated with an increased risk of non-Hodgkin's lymphoma and nonmelanoma skin cancer [47-52].
An effective approach to address the increased risk of malignancy in older IBD patients is through appropriate cancer screening (Table 2). When considering screening in older patients, multiple factors need to be considered, including life expectancy, functional performance status, comorbidities, patient-specific risk factors for individual cancers, psychosocial support, financial status, and patient desires. Screening should only be offered to patients who have good life expectancy (more than 10 years) and are healthy enough to undergo the cancer treatment [53].

\section{IBD-related cancers}

\section{CRC}

Older patients with long-standing IBD-related colitis are at increased risk for CRC. Additionally, older patients are at increased risk for sporadic CRC arising from polyps [13]. In a US population-based case-control study, the incidence of CRC among IBD patients aged 65 and older was 8.2 per 10,000 person-years, compared to 6.1 per 10,000 person-years among those without IBD. The risk of CRC was increased in both UC (OR 1.93, 95\% CI 1.54-2.49) and CD (OR 1.45, 95\% CI 1.08-1.91) [44].

IBD patients with extensive disease, severe inflammation and longer disease duration are at higher risk of CRC [54]. In patients with long-standing disease transitioning to older age, the risk of CRC may be particularly high because of the cumulative effects of age and IBD.

Older-onset IBD may behave differently and the disease extent and duration may be less important. Baars et al found that IBD diagnosis at an older age was related to early CRC (CRC diagnosis within 8 years of IBD diagnosis) and the early CRC was not associated with IBD type, extent of inflammation, pseudopolyps, medication use, or concomitant primary sclerosing cholangitis (PSC) [55]. Other studies have also described a more rapid development of CRC among olderonset IBD patients [56,57]. 
Table 2 Cancer screening for older patients with IBD

\begin{tabular}{|c|c|c|c|}
\hline Cancer & Initial screening & $\begin{array}{l}\text { Subsequent interval } \\
\text { screening }\end{array}$ & Comments \\
\hline Colorectal cancer & $\begin{array}{l}\text { Screening colonoscopy } 8-10 \text { years } \\
\text { following diagnosis but screening } \\
\text { within 1-2 years of diagnosis should be } \\
\text { considered in older-onset IBD }\end{array}$ & $\begin{array}{l}\text { Every } 1-3 \text { years } \\
\text { depending on risk factors }\end{array}$ & $\begin{array}{l}\text { If available, chromoendoscopy with } \\
\text { targeted biopsies can be considered }\end{array}$ \\
\hline $\begin{array}{l}\text { Small intestinal } \\
\text { adenocarcinoma }\end{array}$ & $\begin{array}{l}\text { Consider endoscopic or radiological } \\
\text { screening in long-standing ( }>8 \text { years) } \\
\text { small bowel Crohn's disease }\end{array}$ & Uncertain & Screening unlikely to be cost-effective \\
\hline Cholangiocarcinoma & $\begin{array}{l}\text { Consider screening with ultrasound } \\
\text { or MRCP and cancer antigen 19-9 in } \\
\text { patients with IBD and PSC }\end{array}$ & $\begin{array}{l}\text { Annually in patients } \\
\text { with IBD and PSC }\end{array}$ & No specific guidelines in IBD patients \\
\hline Melanoma and NMSC & $\begin{array}{l}\text { Full skin exams by physician, particularly } \\
\text { upon initiation of thiopurines or } \\
\text { anti-TNF agents }\end{array}$ & Annually & $\begin{array}{l}\text { IBD treatment with anti-TNF agents } \\
\text { and thiopurines may increase risk of } \\
\text { melanoma and NMSC, respectively }\end{array}$ \\
\hline Lymphoma & No screening guidelines & - & $\begin{array}{l}\text { In patients taking } \\
\text { thiopurines, close } \\
\text { surveillance for signs and } \\
\text { symptoms of lymphoma, } \\
\text { such as unexplained fever, } \\
\text { weight loss, night sweats, } \\
\text { fatigue, and swollen lymph } \\
\text { nodes }\end{array}$ \\
\hline
\end{tabular}

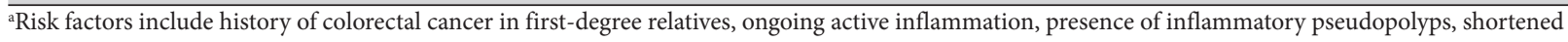
colon, stricture, or concomitant PSC

IBD, inflammatory bowel disease; MRCP, magnetic resonance cholangiopancreatography; NMSC, non-melanoma skin cancer; PSC, primary sclerosing cholangitis; TNF, tumor necrosis factor

Screening and surveillance colonoscopy can reduce the CRC-related mortality in IBD patients. Ananthakrishnan et al reported a reduced risk of CRC and a nearly $70 \%$ reduction in mortality rate from CRC in IBD patients who underwent colonoscopy screening [58].

There are no specific guidelines for CRC screening in older IBD patients. Most authors suggest surveillance strategies based on the duration and extent of colitis in these patients [13,59]. CRC screening guidelines in IBD suggest starting colonoscopy 8-10 years after the diagnosis or onset of symptoms of IBD [54,60,61]. The American Gastroenterology Association (AGA) recommends surveillance examinations every 1 to 3 years thereafter, depending on the risk factors, such as history of CRC in first-degree relatives, ongoing active inflammation, presence of inflammatory pseudopolyps, shortened colon, stricture, or concomitant PSC [54]. The British Society of Gastroenterology recommends yearly, 3-yearly or 5-yearly surveillance colonoscopies, depending on the risk factors. Recommendations include chromoendoscopy with targeted biopsy of abnormal areas, or 2-4 random biopsies from every $10 \mathrm{~cm}$ of the colon [60]. Although these strategies may be applicable to patients with long-standing disease transitioning to older age, revised surveillance strategies may be warranted for older-onset IBD patients, as they are at risk for early CRC [55-57]. In a study by Baars et al, the median duration to CRC diagnosis was 3.5 years in patients with IBD diagnosis at age $>60$ years. This led the authors to suggest an immediate start of surveillance at the time of IBD diagnosis for patients diagnosed with IBD above the age of 45 years [55]. Colonoscopy is an invasive procedure and the risk of colonoscopic complications increases with advanced age. The risk is further increased in the presence of comorbidities [62]. Therefore, clinicians need to consider these factors in the risk-benefit analysis of CRC screening in older IBD patients. Based on the current data, clinicians may consider starting screening colonoscopy within 1-2 years of IBD diagnosis in older-onset IBD patients.

\section{SIA}

Patients with CD are at increased risk of SIA $[45,63]$. Risk factors for SIA in CD include older age, male sex, duration of disease, and associated fistulous disease [45,64].

Currently, there are no screening guidelines for SIA in CD patients. In a prospective French cohort study, the standardized incidence ratio of SIA in patients with small bowel CD was 2.6fold higher in patients with $>8$ years as opposed to $\leq 8$ years of small bowel CD (46.0 vs. 17.8) [63]. This led the authors to suggest endoscopic screening for SIA in patients with longstanding non-resected small bowel CD. Additionally, computed tomographic or magnetic resonance enterography and small bowel capsule endoscopy offer screening possibilities in CD patients; however, further studies are needed to assess their feasibility and efficacy [50].

Although the relative risk of SIA is increased in older patients with $\mathrm{CD}$, the absolute risk is small [45]. Furthermore, the risk of endoscopic complications may be higher in older patients, who often have more comorbidities [62]. Therefore, considering the risks and benefits, SIA screening in all older CD patients with small bowel disease may not be beneficial. 
CC

IBD patients are at increased risk of CC [46]. In a Danish national cohort study, the incidence of $\mathrm{CC}$ in the IBD population was 7.6 per 100,000 person years, compared with 1.9 per 100,000 person years in a non-IBD population. Age had a significant effect on the incidence rate of CC, with the highest incidence rate of 15.2 per 100,000 person years being found in IBD patients aged 60-69 years [46]. A longer duration of IBD is associated with an increased risk for CC development [65]. PSC is often suggested as an intermediate step in CC development [46]. Most CC cases are diagnosed within the first year after the diagnosis of PSC [65]. Although there are no specific guidelines for CC screening in IBD patients, older patients may benefit from an annual ultrasound or magnetic resonance cholangiopancreatography and a cancer antigen 19-9, particularly if other risk factors, such as concomitant PSC are present [50,66]. Further studies are needed to assess the costs and feasibility of CC screening in IBD.

\section{IBD treatment-related cancers}

\section{Lymphoma}

IBD treatment with thiopurines is associated with an increased risk of lymphoma, particularly non-Hodgkin's lymphoma $[47,48,67]$. The risk is even greater in older IBD patients. A recent meta-analysis found that IBD patients over the age of 50 years had the highest absolute risk of lymphoma per year on thiopurines, with a relative risk of 4.78 [67].

Although there are no formal guidelines for lymphoma screening in IBD patients, several strategies have been suggested for reducing the risk of lymphoma in IBD patients. Besides older age and thiopurine therapy, male sex and longer duration of IBD are associated with an increased risk of lymphoma $[47,48,67]$. As the absolute risk of lymphoma is highest in older IBD patients, these patients need to be carefully selected for thiopurine therapy. Thiopurine therapy should only be used in patients with endoscopic verification of moderate-to-severe disease. One possible strategy to reduce the risk of lymphoma may be to limit the use of thiopurines to $1-3$ years $[48,67]$. Some authors have suggested weightbased dose adjustment and thiopurine metabolite monitoring to reduce the risk [48]. Another strategy may be to consider alternative therapy in older IBD patients, methotrexate over thiopurines in CD [13]. If anti-TNF therapy is needed, monotherapy is preferred over concomitant anti-TNF and thiopurine therapy [47].

\section{Skin cancer}

Thiopurine therapy in IBD patients is associated with an increased risk of non-melanoma skin cancer (NMSC) [49,51,52].
In a prospective French cohort study, IBD patients $>65$ years old with current or past thiopurine exposure had the highest incidence of NMSC (4.04 and 5.70 per 1000 patient-years, respectively) [49]. Long et al reported a twofold increase in the risk of NMSC in IBD patients on thiopurine therapy. AntiTNF monotherapy was not associated with an increased risk of NMSC, but concomitant use with thiopurines increased the risk by almost fourfold [51].

The role of IBD therapy in the development of melanoma skin cancer (MSC) is unclear. There is no significant association between thiopurine use and MSC [51,52]. The risk of MSC with anti-TNF therapy is controversial. Long et al reported a nearly twofold increased risk of melanoma with anti-TNF therapy. The incidence of melanoma increased with advancing age, regardless of IBD status [51]. However, anti-TNF therapy was not associated with an increased risk of MSC in other studies [68]. Further studies are needed to delineate the risk of MSC in older IBD patients.

Older IBD patients, particularly those on thiopurine therapy, should be educated about the risk of skin cancer. Preventive strategies are critical and may decrease the burden of skin cancer in IBD patients. Primary prevention strategies include limiting sun exposure, use of sun-protective clothing, broad-spectrum sunscreen, and reduction or elimination of modifiable risk factors. In addition to thiopurine therapy, older age, male sex, fair skin, high ultraviolet exposure, and a personal or family history of skin cancer are associated with an increased risk of NMSC in IBD patients [49,52,69]. It is unclear if the risk of NMSC persists after discontinuation of thiopurine therapy. In the CESAME study cohort, past thiopurine exposure significantly increased the risk of NMSC in IBD patients, indicating persistent risk following thiopurine withdrawal [49]. However, in a retrospective cohort study involving UC patients, Abbas et al found that the risk of NMSC reduced to pre-exposure levels after discontinuation of thiopurine therapy [52]. One possible strategy to reduce the risk of NMSC may be withdrawal of thiopurine therapy in older IBD patients after a period of deep remission [52]. Another strategy may be to consider alternative therapy, especially in older Caucasian men with a personal or family history of skin cancer. Secondary prevention measures include routine skin screening examinations for patients at risk. Although there are no specific guidelines regarding skin cancer screening in IBD, most experts recommend an annual dermatology examination by a physician $[50,69]$. In a study of a hypothetical cohort of CD patients, annual NMSC screening was cost-effective and led to the early detection of nearly $94 \%$ of incident NMSC cases [70].

\section{Bone health}

Older IBD patients are at increased risk of osteoporosis and fracture [71-73]. In a population-based study in CD patients from the US, aging significantly increased the risk of fracture, with a $30 \%$ increase in the risk for every 10 -year increase in age [71]. These fractures can adversely affect the health and well being of older IBD patients. In a study based on a 
nationwide inpatient database from the US, Ananthakrishnan et al reported 1653 hospitalizations for hip, vertebral or wrist fractures in IBD patients, accounting for an estimated 10,461 hospitalization days and US\$46 million in total hospitalization charges. Old age was associated with the highest risk for fracture-related hospitalizations in IBD patients (OR 28.8, 95\% CI 12.3-67.6). Compared with hospitalized IBD controls without fractures, IBD patients with fractures had significantly longer hospital stays, with higher hospitalization costs and inhospital mortality [72].

Older age, ongoing intestinal inflammation, and corticosteroids can predispose IBD patients to osteoporosis. Other risk factors for osteoporosis in IBD include low body mass index, immobilization or sedentary lifestyle, previous fragility fracture, hypogonadism, smoking, excess alcohol consumption, malnutrition, malabsorption and deficiency of calcium and vitamin D [73]. The AGA guidelines suggest screening IBD patients for decreased bone mineral density with dual-energy X-ray absorptiometry scanning in the presence of one or more risk factors (Table 3) [74].

Besides screening at-risk IBD patients, clinicians should emphasize primary prevention measures to promote and maintain bone health in older IBD patients. All patients with IBD should be educated about the importance of lifestyle changes, such as regular weight-bearing exercise, smoking cessation, and minimizing alcohol intake [61]. Osteoporotic patients or patients at risk for osteoporosis should receive adequate Vitamin D (400-800 IU/day) and calcium (up to $1500 \mathrm{mg} /$ day) supplementation $[24,74]$. The use of corticosteroids should be minimized and steroid-sparing strategies should be developed upon initiation of corticosteroids. Budesonide sustainedrelease capsules $\left(\right.$ Enterocort $\left.^{\circledast}\right)$ in mild to moderate ileal or right colonic $\mathrm{CD}$ and budesonide extended-release tablets $\left(\right.$ Uceris $\left.^{\circledast}\right)$ in mild to moderate UC are preferred over systemic corticosteroids, as they have less systemic absorption and effect on bone metabolism [75-77]. The AGA guidelines suggest bisphosphonate therapy in IBD patients with osteoporosis, atraumatic fractures, and patients on corticosteroids for $>3$ months [74]. For post-menopausal osteoporosis in IBD patients, estrogen therapy, a selective estrogen receptor modulator or calcitonin may be considered [74]. Osteoporosis associated with hypogonadism in male IBD patients should be treated with testosterone. Consultation with a bone disease specialist or an endocrinologist should be considered in managing older IBD patients with significant bone disease.

\section{Mental health}

IBD carries significant psychological and social implications for patients. Moreover, IBD patients have higher rates of anxiety

Table 3 Health maintenance issues for older patients with inflammatory bowel disease

\begin{tabular}{|c|c|c|}
\hline Health issue & Monitoring & Comment \\
\hline Bone health & $\begin{array}{l}\text { Screen at-risk patients for } \\
\text { decreased bone mineral density }\end{array}$ & $\begin{array}{l}\text { Prevention strategies: } \\
\text { Minimize corticosteroid use } \\
\text { Promote lifestyle changes, such as weight bearing activity, smoking cessation } \\
\text { Calcium and vitamin D supplementation } \\
\text { Bisphosphonate therapy as indicated } \\
\text { Consider consultation with bone disease specialist or endocrinologist if } \\
\text { significant bone disease }\end{array}$ \\
\hline Mental health & $\begin{array}{l}\text { Assess psychological status at } \\
\text { regular visits }\end{array}$ & $\begin{array}{l}\text { Refer to a specialist } \\
\text { (psychiatrist, psychologist) if } \\
\text { significant psychological disorder }\end{array}$ \\
\hline Nutritional status & $\begin{array}{l}\text { Record weight change and } \\
\text { inquire regarding food intake } \\
\text { during regular visits }\end{array}$ & $\begin{array}{l}\text { Annual serum vitamin } B 12 \text {, } \\
\text { vitamin } D \text {, iron and folate levels in patients with small bowel Crohn's disease } \\
\text { Refer to a registered dietician if malnutrition }\end{array}$ \\
\hline $\begin{array}{l}\text { Smoking } \\
\text { cessation }\end{array}$ & Assess at regular visits & $\begin{array}{l}\text { Smoking cessation interventions: } \\
\text { Patient education and counseling } \\
\text { Nicotine replacement therapy, bupropion or varenicline }\end{array}$ \\
\hline $\begin{array}{l}\text { Venous } \\
\text { thromboembolism }\end{array}$ & $\begin{array}{l}\text { Assess for thromboembolism, } \\
\text { particularly during flares and } \\
\text { hospitalizations }\end{array}$ & $\begin{array}{l}\text { Thromboprophylaxis recommended for all hospitalized patients } \\
\text { May consider outpatient prophylaxis during moderate to severe disease flares, } \\
\text { particularly for patients with a previous thromboembolism who are no longer on } \\
\text { anticoagulation }\end{array}$ \\
\hline Ocular health & Annual ophthalmologic exams & $\begin{array}{l}\text { Risk factors include the extent of intestinal disease (colitis or ileocolitis), disease } \\
\text { activity, presence of associated arthritis and long-term corticosteroid therapy } \\
\text { (>3 months) }\end{array}$ \\
\hline Oral health & $\begin{array}{l}\text { Annual or biannual dental } \\
\text { exams }\end{array}$ & $\begin{array}{l}\text { Risk factors include smoking, } \\
\text { perianal disease and high disease activity in Crohn's disease }\end{array}$ \\
\hline
\end{tabular}

${ }^{a}$ Risk factors include post-menopausal state, men over the age of 50, $>3$ months of corticosteroid use, history of a low-trauma fracture, or hypogonadism.

${ }^{b}$ Indications include patients with osteoporosis, osteoporotic fragility fractures, and patients on chronic corticosteroid therapy 
and/or depression $[78,79]$. In a population-based study, IBD patients had a significantly higher risk of major depression compared to age- and gender-matched controls (OR 2.2, 95\% CI 1.64-2.95) [79]. Older IBD patients, in particular, are at increased risk of developing depression [80]. In the general population, nearly $7 \%$ of older adults experience mood disorders [81]. In the older IBD population, the prevalence of depression is around $23 \%$. Lower education level, higher corticosteroid use, and lower exercise levels are associated with depression in these patients [80]. Psychological health has important implications for other disease factors. The presence of depression is associated with higher IBD disease activity, frequent flares, lower remission rates, and decreased health-related quality of life, regardless of the severity of the underlying disease $[78,80,82]$.

The European Crohn's and Colitis Organisation (ECCO) consensus guidelines recommend assessment of the patient's psychosocial status and need for additional psychological care at regular visits, with psychotherapy being provided if indicated [83]. The Assessment of the Demand for Additional Psychological Treatment (ADAPT) questionnaire, developed and validated in IBD patients, can be used to assess the need for psychological care in IBD patients [84]. The choice of psychotherapeutic intervention depends on the psychological disorder, and should be delivered in consultation with a specialist (psychiatrist, psychologist).

Corticosteroid use in IBD can also cause psychiatric side effects. Akerkar et al reported a sevenfold increased risk of mental status changes in CD patients $>50$ years old treated with corticosteroids compared to those not receiving corticosteroid treatment. The risk was similar for patients $<65$ and $\geq 65$ years of age [85]. Treatment involves targeting the specific psychiatric symptoms and discontinuation of corticosteroids, when possible.

\section{Nutritional status}

Older IBD patients, particularly those with CD, are at increased risk of protein-energy malnutrition and micronutrient deficiencies. In a study based on a national inpatient database in the US, IBD patients $\geq 65$ years old were more likely to have malnutrition than IBD patients $<65$ years old ( $7.3 \%$ vs. $5.4 \%$ ). Furthermore, malnutrition was associated with higher in-hospital mortality (OR 1.86, 95\% CI 1.38-2.51) [86]. In another study, up to $18 \%$ of older IBD patients were found to have deficiencies of vitamin B12, iron and vitamin D. Nutritional deficiencies correlated with the duration of disease in CD, but not in UC [87]. Malnutrition in $\mathrm{CD}$ is associated with increased rates of sepsis, pneumonia, postoperative complications, mortality, prolonged hospital stay, and higher costs [88].

Nutrition screening and implementation of targeted nutrition plans can reduce the risk of malnutrition. Inquiry about food intake and weight change, along with the measurements of body weights during clinic visits, can help clinicians to identify patients at nutritional risk. In patients with small bowel CD in remission, serum vitamin B12, vitamin D, iron and folate levels should be measured annually $[24,87,88]$. Patients at risk of malnutrition should be referred to a registered dietician to arrange a treatment plan.

\section{Smoking cessation}

Smoking rates are lower in patients $\geq 65$ years old than in younger adults, but the cumulative effects of smoking in the elderly lead to higher rates of lung cancer and mortality related to chronic obstructive lung disease [89]. Smoking in $\mathrm{CD}$ patients is associated with a more severe disease course, increased relapse rates, need for corticosteroids and immunemodifying agents, and a higher risk of hospitalization and surgery [90,91]. In contrast, smoking in UC patients is associated with lower rates of disease exacerbation, hospitalization and colectomy [90,92]. However, a recent study failed to demonstrate a substantial benefit from smoking in UC [91]. The risk of developing CD is not significantly increased after age 55 years [90]. Nonetheless, smoking has detrimental effects on other aspects of health in IBD patients, such as bone health, cancer prevention, venous thromboembolism, and cardiovascular and pulmonary disease.

IBD patients who are informed about the effects of smoking are more likely to quit [93]. Although older smokers are less likely than younger smokers to attempt quitting, they are more likely to be successful. Older smokers are more responsive to targeted smoking cessation programs and are more likely to use cessation assistance, partly explaining their greater cessation success [89]. In a cost-utility analysis using a Markov model, Coward et al found that smoking cessation programs were cost-effective and could improve health outcomes in CD patients [94]. Therefore, smoking cessation is an important topic of discussion between providers and older IBD patients.

\section{Venous thromboembolism (VTE) prevention}

Patients with IBD have a 2- to 3-fold higher risk of VTE compared to the general population [95-98]. IBD-related factors, such as an active inflammation, hospitalization, malignancy, surgery, vitamin deficiency, corticosteroid treatment and dehydration, increase the risk of VTE in IBD patients $[97,99,100]$. Advanced age is an additional risk factor for VTE. In a study based on a nationwide inpatient database from the US, aging significantly increased the risk of VTE in IBD patients, with a $20 \%$ increase in the risk for every 10 year increase in age. Furthermore, VTE in IBD patients was associated with greater mortality, a longer length of hospital stay, and higher hospitalization cost [96].

IBD guidelines recommend anticoagulant thromboprophylaxis in hospitalized IBD patients [83,98]. In a multi-institutional cohort study of 2788 IBD patients with at least one IBD-related hospitalization, pharmacological 
thromboprophylaxis during the index hospital stay was associated with a significantly lower risk of post-hospitalization VTE (HR 0.46, 95\% CI 0.22-0.97) [99].

There are no specific guidelines for VTE prophylaxis in older IBD patients. Clinicians should implement intervention strategies to reduce or remove modifiable risk factors associated with VTE. Smoking cessation, weight reduction in obese patients, adequate hydration, early mobilizationparticularly in a postoperative setting-and frequent ambulation during long-distance travel should be encouraged. Timely diagnosis and treatment of infections, limiting the use of venous catheters, correction of vitamin deficiency (B6, B12 and folic acid), and prompt treatment of active disease are other important measures for preventing VTE in IBD patients [100]. As the absolute risk of VTE increases with age and IBD flares in an ambulatory setting, some authors have suggested the use of outpatient VTE prophylaxis in older, non-hospitalized IBD patients during disease flares [95,97]. Consensus guidelines recommend against the routine use of anticoagulant thromboprophylaxis during an outpatient IBD flare. However, anticoagulation may be considered during moderate to severe IBD flares in IBD outpatients who are no longer on anticoagulation [98].

\section{Eye health}

IBD patients can develop eye disease, either as an extraintestinal manifestation of IBD or as a complication of IBD therapy. Although conjunctivitis, episcleritis, scleritis, and uveitis are the most common ophthalmologic complications of IBD, posterior uveitis, intraretinal hemorrhages, vasculitis, choriditis, optic neuropathy, and vaso-occlusive phenomena may also occur [101]. A prospective clinical study of 116 IBD patients reported no significant association of age with the development of ocular complications in IBD [102]. However, a population-based IBD cohort study found that patients $>40$ years old were more likely to have iritis/uveitis than those $<40$ years old [103]. Vision loss in the elderly can cause a significant decline in function and is related to falls and cognitive decline. Early diagnosis and treatment of ocular disease can prevent significant morbidity from vision loss. The AGA guidelines recommend annual ophthalmologic exams for patients on long-term corticosteroid therapy ( $>3$ months) [75]. Since the burden of ocular disease is high in the elderly, older IBD patients are likely to benefit from annual ophthalmologic exams.

\section{Oral health}

IBD patients have a high prevalence of oral and dental diseases, such as gingivitis, dental caries, periodontitis, oral ulcers, and dry mouth [104,105]. Not surprisingly, IBD patients need more frequent dental care [104]. In one case-control study, smoking increased the risk of gingivitis, whereas brushing teeth regularly decreased the risk in IBD patients [105]. A recent study found an increased risk of oral cancers, particularly tongue cancer, in IBD patients [106]. In addition to regular brushing, flossing and appropriate denture care, annual or biannual dental exams should be encouraged in older IBD patients.

\section{Polypharmacy/monitoring for adverse effects of IBD treatment}

Advanced age is often associated with multimorbidity and polypharmacy. Older IBD patients are prescribed on an average 7-9 routine medications $[87,107]$. In a study in CD patients, major polypharmacy ( $\geq 5$ medications) was noted in $50 \%$ of patients, with advanced age significantly increasing the risk (OR 1.9, 95\% CI 1.2-3.4) [108]. A retrospective study in older IBD patients noted major polypharmacy in nearly $22 \%$ patients [87]. However, in a cohort study from a referral center, approximately $44 \%$ of older IBD patients had severe polypharmacy ( $\geq 10$ routine medications) [107].

With increasing polypharmacy, there is greater potential for adverse drug events, drug-drug interactions, medicationrelated errors, non-adherence, and decreased quality of life $[38,107,108]$. Parian et al reported at least one potential medication interaction in almost two-thirds of older IBD patients [107]. Cross et al reported adverse drug reactions in nearly $55 \%$ of $\mathrm{CD}$ patients. In addition, polypharmacy correlated with decreased quality of life [108]. Therefore, it is important to review the medication list of older IBD patients at regular intervals to eliminate unnecessary or inappropriate medications.

Multimorbidity and polypharmacy, along with alterations in pharmacokinetics and pharmacodynamics, increase the risk of adverse drug reactions in older IBD patients. Agerelated increases in body fat and decreases in lean body mass and total body water can alter the distribution of lipophilic and hydrophilic drugs. Additionally, age-related physiological changes, such as increased gastric $\mathrm{pH}$, delayed gastric emptying, decreased absorption surface, gastrointestinal motility, hepatic mass and blood flow, renal blood flow and glomerular filtration rate can alter drug absorption, metabolism and elimination in the elderly [109]. Renal elimination of sulfasalazine, corticosteroids, and methotrexate may be slower in older IBD patients [13]. Therefore, older IBD patients should be closely monitored for any adverse drug reactions. Clinicians should also be vigilant about potential drug-drug interactions while starting these patients on any new medication.

Based on the level of disease severity, patients should undergo routine office visits at least every 3-6 months. Providers should consider obtaining baseline laboratory tests (complete blood count, metabolic profile, liver function testing, C-reactive protein, sedimentation rate). Patients on medical therapy should undergo laboratory testing every 1-6 months depending on their treatment regimen (Table 4) $[11,24,38,75,110,111]$. 
Table 4 Medication-specific health issues for older patients with inflammatory bowel disease $[11,24,38,75,110,111]$

\begin{tabular}{|c|c|c|}
\hline Specific medications & Safety concerns & Comment \\
\hline Aminosalicylates & Nephrotoxicity and interstitial nephritis & $\begin{array}{l}\text { Overall risk of renal insufficiency is minimal } \\
\text { Renal function testing every 3-6 months in the first year of therapy and } \\
\text { then annually }\end{array}$ \\
\hline Corticosteroids & $\begin{array}{l}\text { Adverse events from corticosteroid use } \\
\text { include sleep and mood disturbances, } \\
\text { glucose intolerance, hypertension, } \\
\text { cataracts, glaucoma, osteoporosis, } \\
\text { myopathy, edema, and increased } \\
\text { susceptibility to infections }\end{array}$ & $\begin{array}{l}\text { Adverse events are more frequent and severe in the elderly } \\
\text { Recommended tests include } 25-\mathrm{OH} \text { vitamin D level, metabolic panel, } \\
\text { and glucose }\end{array}$ \\
\hline Thiopurines & $\begin{array}{l}\text { The major concerning side effect is bone } \\
\text { marrow suppression } \\
\text { Other side effects include mild } \\
\text { gastrointestinal side effects, pancreatitis, } \\
\text { hepatotoxicity, and non-specific reactions, } \\
\text { such as fever, rash, and arthralgia }\end{array}$ & $\begin{array}{l}\text { No significant differences in efficacy, metabolism, and toxicity of } \\
\text { thiopurine therapy between older and younger patients } \\
\text { A thiopurine methyl transferase genotype and enzyme activity } \\
\text { testing prior to initiation of therapy; CBC and liver function testing } \\
\text { at least every other week when initiating therapy as long as doses of } \\
\text { medications are being adjusted, thereafter at least every } 3 \text { months }\end{array}$ \\
\hline Methotrexate & $\begin{array}{l}\text { Bone marrow suppression, hepatic } \\
\text { fibrosis, alopecia, and hypersensitivity } \\
\text { pneumonitis }\end{array}$ & $\begin{array}{l}\text { Periodic } \mathrm{CBC} \text { and liver function testing; folate supplementation during } \\
\text { therapy }\end{array}$ \\
\hline Cyclosporine & $\begin{array}{l}\text { Common side effects include } \\
\text { hypertension, seizure, tremor, } \\
\text { paresthesias, gingival hyperplasia, } \\
\text { hypertrichosis, nephrotoxicity, electrolyte } \\
\text { abnormalities, and opportunistic } \\
\text { infections }\end{array}$ & $\begin{array}{l}\mathrm{CBC} \text {, serum chemistries, and cyclosporine levels regularly; Prophylaxis } \\
\text { against Pneumocystis carinii is recommended }\end{array}$ \\
\hline Biologics & $\begin{array}{l}\text { Potential adverse effects include } \\
\text { infections, heart failure, dermatological } \\
\text { manifestations, infusion reactions and } \\
\text { neurological manifestations }\end{array}$ & $\begin{array}{l}\text { Conflicting evidence on efficacy of biologics among the elderly } \\
\text { (European studies reported similar response rates in elderly and } \\
\text { younger patients; however, a US study reported lower response rates in } \\
\text { elderly compared with younger patients) } \\
\text { Elderly patients may be more susceptible to adverse effects } \\
\text { Prior to initiation of therapy, hepatitis serologies and tuberculosis } \\
\text { screening with tuberculin skin test or Quantiferon-TB Gold test; CBC } \\
\text { and liver function testing every 3-6 months while on maintenance } \\
\text { therapy }\end{array}$ \\
\hline
\end{tabular}

\section{Concluding remarks}

Older IBD patients often have a higher risk and are more vulnerable to adverse events associated with their disease and treatment. Therefore, heath maintenance strategies are imperative. Infections, malignancy, bone disease, psychological disorders, venous thromboembolism, malnutrition and polypharmacy are issues of particular concern in older IBD patients. Despite the increased burden of preventable diseases in the IBD population, most IBD patients do not receive routine health maintenance. Older IBD patients, particularly those on biologics and/or immune-modifying agents, may have a decreased immune response to vaccinations. Clinicians should consider vaccinating these patients before the initiation of immunosuppressive therapy. Cancer screening should only be offered to patients who have good life expectancy and are healthy enough to undergo cancer treatment. Additionally, preventive strategies against osteoporosis and osteoporotic fractures, VTE, malnutrition, ocular disease and depression may have significant health benefits for older IBD patients. Further studies of different healthcare maintenance strategies in IBD patients will elucidate the need for additional agerelated guidelines.

\section{References}

1. Nichol KL, Nordin JD, Nelson DB, Mullooly JP, Hak E. Effectiveness of influenza vaccine in the community-dwelling elderly. N Engl J Med 2007;357:1373-1381.

2. van Hees F, Habbema JD, Meester RG, Lansdorp-Vogelaar I, van Ballegooijen M, Zauber AG. Should colorectal cancer screening be considered in elderly persons without previous screening? A cost-effectiveness analysis. Ann Intern Med 2014;160:750-759.

3. Beckett N, Peters R, Tuomilehto J, et al; HYVET Study Group. Immediate and late benefits of treating very elderly people with hypertension: results from active treatment extension to Hypertension in the Very Elderly randomised controlled trial. BMJ 2011;344:d7541.

4. Shenson D, Bolen J, Adams M. Receipt of preventive services by elders based on composite measures, 1997-2004. Am J Prev Med 2007;32:11-18. 
5. Selby L, Kane S, Wilson J, et al. Receipt of preventive health services by IBD patients is significantly lower than by primary care patients. Inflamm Bowel Dis 2008;14:253-258.

6. Selby L, Hoellein A, Wilson JF. Are primary care providers uncomfortable providing routine preventive care for inflammatory bowel disease patients? Dig Dis Sci 2011;56:819-824.

7. Curtis JR, Arora T, Narongroeknawin P, et al. The delivery of evidence-based preventive care for older Americans with arthritis. Arthritis Res Ther 2010;12:R144.

8. Caldera F, Saha S, Wald A, et al. Comparing guideline-based care quality for inflammatory bowel disease and rheumatoid arthritis patients within a medical home. Expert Rev Gastroenterol Hepatol 2016;10:759-766

9. Molodecky NA, Soon IS, Rabi DM, et al. Increasing incidence and prevalence of the inflammatory bowel diseases with time, based on systematic review. Gastroenterology 2012;142:46-54.

10. Lichtenstein GR, Feagan BG, Cohen RD, et al. Serious infection and mortality in patients with Crohn's disease: more than 5 years of follow-up in the TREAT ${ }^{\mathrm{TM}}$ registry. Am J Gastroenterol 2012;107:1409-1422.

11. Cottone M, Kohn A, Daperno M, et al. Advanced age is an independent risk factor for severe infections and mortality in patients given anti-tumor necrosis factor therapy for inflammatory bowel disease. Clin Gastroenterol Hepatol 2011;9:30-35.

12. Ananthakrishnan AN, McGinley EL. Infection-related hospitalizations are associated with increased mortality in patients with inflammatory bowel diseases. J Crohns Colitis 2013;7:107-112.

13. Katz S, Pardi DS. Inflammatory bowel disease of the elderly: frequently asked questions (FAQs). Am J Gastroenterol 2011;106:1889-1897.

14. Sands BE, Cuffari C, Katz J, et al. Guidelines for immunizations in patients with inflammatory bowel disease. Inflamm Bowel Dis 2004;10:677-692.

15. Horton HA, Kim H, Melmed GY. Vaccinations in older adults with gastrointestinal diseases. Clin Geriatr Med 2014;30:17-28.

16. Gisbert JP, Villagrasa JR, Rodríguez-Nogueiras A, Chaparro M. Efficacy of hepatitis B vaccination and revaccination and factors impacting on response in patients with inflammatory bowel disease. Am J Gastroenterol 2012;107:1460-1466.

17. Goodwin K, Viboud C, Simonsen L. Antibody response to influenza vaccination in the elderly: a quantitative review. Vaccine 2006;24:1159-1169.

18. Launay O, Abitbol V, Krivine A, et al; MICIVAX Study Group. Immunogenicity and safety of influenza vaccine in inflammatory bowel disease patients treated or not with immunomodulators and/or biologics: A two-year prospective study. J Crohns Colitis 2015;9:1096-1107.

19. Fiorino G, Peyrin-Biroulet L, Naccarato P, et al. Effects of immunosuppression on immune response to pneumococcal vaccine in inflammatory bowel disease: a prospective study. Inflamm Bowel Dis 2012;18:1042-1047.

20. Hainz U, Jenewein B, Asch E, Pfeiffer KP, Berger P, GrubeckLoebenstein B. Insufficient protection for healthy elderly adults by tetanus and TBE vaccines. Vaccine 2005;23:3232-3235.

21. Dezfoli S, Horton HA, Thepyasuwan N, et al. Combined immunosuppression impairs immunogenicity to tetanus and pertussis vaccination among patients with inflammatory bowel disease. Inflamm Bowel Dis 2015;21:1754-1760.

22. Wasan SK, Baker SE, Skolnik PR, Farraye FA. A practical guide to vaccinating the inflammatory bowel disease patient. Am J Gastroenterol 2010;105:1231-1238.

23. Melmed GY. Vaccination strategies for patients with inflammatory bowel disease on immunomodulators and biologics. Inflamm Bowel Dis 2009;15:1410-1416.

24. Ooi CJ, Makharia GK, Hilmi I, et al; Asia Pacific Association of Gastroenterology (APAGE) Working Group on Inflammatory
Bowel Disease. Asia-Pacific consensus statements on Crohn's disease. Part 2: Management. J Gastroenterol Hepatol 2016;31:56-68.

25. Harpaz R, Ortega-Sanchez IR, Seward JF; Advisory Committee on Immunization Practices (ACIP) Centers for Disease Control and Prevention (CDC). Prevention of herpes zoster: Recommendations of the advisory committee on immunization practices (ACIP). MMWR Recomm Rep 2008;57:1-30.

26. Centers for disease control and prevention. Recommended adult immunization schedule for adults aged 19 years or older, by vaccine and age group-United States, 2016. http://www.cdc. gov.ezproxy1.library.arizona.edu/vaccines/schedules/downloads/ adult/adult-combined-schedule.pdf. Accessed 1 February 2017.

27. Cullen G, Baden RP, Cheifetz AS. Varicella zoster virus infection in inflammatory bowel disease. Inflamm Bowel Dis 2012;18:2392-2403.

28. Rahier JF, Magro F, Abreu C, et al; European Crohn's and Colitis Organisation (ECCO). Second European evidence-based consensus on the prevention, diagnosis and management of opportunistic infections in inflammatory bowel disease. J Crohns Colitis 2014;8:443-468.

29. Gupta G, Lautenbach E, Lewis JD. Incidence and risk factors for herpes zoster among patients with inflammatory bowel disease. Clin Gastroenterol Hepatol 2006;4:1483-1490.

30. Zhang J, Xie F, Delzell E, et al. Association between vaccination for herpes zoster and risk of herpes zoster infection among older patients with selected immune-mediated diseases. JAMA 2012;308:43-49.

31. Lal H, Cunningham AL, Godeaux O, et al; ZOE-50 Study Group. Efficacy of an adjuvanted herpes zoster subunit vaccine in older adults. N Engl J Med 2015;372:2087-2096.

32. Park SH, Yang SK, Park SK, et al. Efficacy of hepatitis A vaccination and factors impacting on seroconversion in patients with inflammatory bowel disease. Inflamm Bowel Dis 2014;20:69-74.

33. Nichol KL, Margolis KL, Wuorenma J, Von Sternberg T. The efficacy and cost effectiveness of vaccination against influenza among elderly persons living in the community. $N$ Engl J Med 1994;331:778-784.

34. DiazGranados CA, Dunning AJ, Kimmel M, et al. Efficacy of high-dose versus standard-dose influenza vaccine in older adults. N Engl J Med 2014;371:635-645.

35. Centers for disease control and prevention. 2011. Active bacterial core surveillance report, emerging infections program network, Streptococcus pneumoniae, 2010. http://www.cdc.gov/ abcs/reports-findings/survreports/spneu10-orig.pdf. Accessed 1 February 2017.

36. Long MD, Martin C, Sandler RS, Kappelman MD. Increased risk of pneumonia among patients with inflammatory bowel disease. Am J Gastroenterol 2013;108:240-248.

37. Izurieta HS, Sutter RW, Strebel PM, et al. Tetanus surveillanceUnited States, 1991-1994. MMWR CDC Surveill Summ 1997;46:15-25.

38. Ha CY, Katz S. Clinical outcomes and management of inflammatory bowel disease in the older patient. Curr Gastroenterol Rep 2013;15:310.

39. Esteve M, Saro C, González-Huix F, Suarez F, Forné M, Viver JM. Chronic hepatitis $\mathrm{B}$ reactivation following infliximab therapy in Crohn's disease patients: need for primary prophylaxis. Gut 2004;53:1363-1365.

40. Vida Pérez L, Gómez Camacho F, García Sánchez V, et al. [Adequate rate of response to hepatitis $B$ virus vaccination in patients with inflammatory bowel disease]. Med Clin (Barc) 2009;132:331-335.

41. Cardell K, Akerlind B, Sällberg M, Frydén A. Excellent response rate to a double dose of the combined hepatitis $\mathrm{A}$ and $\mathrm{B}$ vaccine in previous nonresponders to hepatitis B vaccine. J Infect Dis 
2008;198:299-304.

42. Stobaugh DJ, Deepak P, Ehrenpreis ED. Hospitalizations for vaccine preventable pneumonias in patients with inflammatory bowel disease: a 6-year analysis of the nationwide inpatient sample. Clin Exp Gastroenterol 2013;6:43-49.

43. Bernstein CN, Blanchard JF, Kliewer E, Wajda A. Cancer risk in patients with inflammatory bowel disease: a population-based study. Cancer 2001;91:854-862.

44. Shaukat A, Virnig DJ, Salfiti NI, Howard DH, Sitaraman SV, Liff JM. Is inflammatory bowel disease an important risk factor among older persons with colorectal cancer in the United States? A population-based case-control study. Dig Dis Sci 2011;56:2378-2383.

45. Shaukat A, Virnig DJ, Howard D, Sitaraman SV, Liff JM, Lederle FA. Crohn's disease and small bowel adenocarcinoma: a population-based case-control study. Cancer Epidemiol Biomarkers Prev 2011;20:1120-1123.

46. Erichsen R, Jepsen P, Vilstrup H, Ekbom A, Sørensen HT. Incidence and prognosis of cholangiocarcinoma in Danish patients with and without inflammatory bowel disease: a national cohort study, 1978-2003. Eur J Epidemiol 2009;24:513-520.

47. Beaugerie L, Brousse N, Bouvier AM, et al; CESAME Study Group. Lymphoproliferative disorders in patients receiving thiopurines for inflammatory bowel disease: a prospective observational cohort study. Lancet 2009;374:1617-1625.

48. Khan N, Abbas AM, Lichtenstein GR, Loftus EV Jr, Bazzano LA. Risk of lymphoma in patients with ulcerative colitis treated with thiopurines: a nationwide retrospective cohort study. Gastroenterology 2013;145:1007-1015.

49. Peyrin-Biroulet L, Khosrotehrani K, Carrat F, et al; Cesame Study Group. Increased risk for nonmelanoma skin cancers in patients who receive thiopurines for inflammatory bowel disease. Gastroenterology 2011;141:1621-1628.e1-e5.

50. Parian A, Lazarev M. Who and how to screen for cancer in at-risk inflammatory bowel disease patients. Expert Rev Gastroenterol Hepatol 2015;9:731-746.

51. Long MD, Martin CF, Pipkin CA, Herfarth HH, Sandler RS, Kappelman MD. Risk of melanoma and nonmelanoma skin cancer among patients with inflammatory bowel disease. Gastroenterology 2012;143:390-399.

52. Abbas AM, Almukhtar RM, Loftus EV Jr, Lichtenstein GR, Khan N. Risk of melanoma and non-melanoma skin cancer in ulcerative colitis patients treated with thiopurines: a nationwide retrospective cohort. Am J Gastroenterol 2014;109:1781-1793.

53. Wilt TJ, Harris RP, Qaseem A; High Value Care Task Force of the American College of Physicians. Screening for cancer: advice for high-value care from the American College of Physicians. Ann Intern Med 2015;162:718-725.

54. Farraye FA, Odze RD, Eaden J, et al; AGA Institute Medical Position Panel on Diagnosis and Management of Colorectal Neoplasia in Inflammatory Bowel Disease. AGA medical position statement on the diagnosis and management of colorectal neoplasia in inflammatory bowel disease. Gastroenterology 2010;138:738-745.

55. Baars JE, Kuipers EJ, van Haastert M, Nicolaï JJ, Poen AC, van der Woude CJ. Age at diagnosis of inflammatory bowel disease influences early development of colorectal cancer in inflammatory bowel disease patients: a nationwide, long-term survey. J Gastroenterol 2012;47:1308-1322.

56. Karvellas CJ, Fedorak RN, Hanson J, Wong CK. Increased risk of colorectal cancer in ulcerative colitis patients diagnosed after 40 years of age. Can J Gastroenterol 2007;21:443-446.

57. Brackmann S, Andersen SN, Aamodt G, et al. Relationship between clinical parameters and the colitis-colorectal cancer interval in a cohort of patients with colorectal cancer in inflammatory bowel disease. Scand J Gastroenterol 2009;44:46-55.

58. Ananthakrishnan AN, Cagan A, Cai T, et al. Colonoscopy is associated with a reduced risk for colon cancer and mortality in patients with inflammatory bowel diseases. Clin Gastroenterol Hepatol 2015;13:322-329.

59. Gisbert JP, Chaparro M. Systematic review with meta-analysis: inflammatory bowel disease in the elderly. Aliment Pharmacol Ther 2014;39:459-477.

60. Cairns SR, Scholefield JH, Steele RJ, et al; Association of Coloproctology for Great Britain and Ireland. Guidelines for colorectal cancer screening and surveillance in moderate and high risk groups (update from 2002). Gut 2010;59:666-689.

61. Ooi CJ, Fock KM, Makharia GK, et al; Asia Pacific Association of Gastroenterology Working Group on Inflammatory Bowel Disease. The Asia-Pacific consensus on ulcerative colitis. J Gastroenterol Hepatol 2010;25:453-468.

62. Bielawska B, Day AG, Lieberman DA, Hookey LC. Risk factors for early colonoscopic perforation include non-gastroenterologist endoscopists: a multivariable analysis. Clin Gastroenterol Hepatol 2014; 12:85-92.

63. Elriz K, Carrat F, Carbonnel F, Marthey L, Bouvier AM, Beaugerie L; CESAME study group. Incidence, presentation, and prognosis of small bowel adenocarcinoma in patients with small bowel Crohn's disease: a prospective observational study. Inflamm Bowel Dis 2013;19:1823-1826.

64. Bernstein D, Rogers A. Malignancy in Crohn's disease. Am J Gastroenterol 1996;91:434-440.

65. Boberg KM, Bergquist A, Mitchell S, et al. Cholangiocarcinoma in primary sclerosing cholangitis: risk factors and clinical presentation. Scand J Gastroenterol 2002;37:1205-1211.

66. Chapman R, Fevery J, Kalloo A, et al; American Association for the Study of Liver Diseases. Diagnosis and management of primary sclerosing cholangitis. Hepatology 2010;51:660-678.

67. Kotlyar DS, Lewis JD, Beaugerie L, et al. Risk of lymphoma in patients with inflammatory bowel disease treated with azathioprine and 6-mercaptopurine: a meta-analysis. Clin Gastroenterol Hepatol 2015;13:847-858.e4; quiz e48-e50.

68. Kopylov U, Vutcovici M, Kezouh A, Seidman E, Bitton A, Afif W. Risk of lymphoma, colorectal and skin cancer in patients with IBD treated with immunomodulators and biologics: a Quebec claims database study. Inflamm Bowel Dis 2015;21:1847-1853.

69. Magro F, Peyrin-Biroulet L, Sokol H, et al. Extra-intestinal malignancies in inflammatory bowel disease: Results of the 3rd ECCO pathogenesis scientific workshop (III). J Crohns Colitis 2014;8:31-44.

70. Okafor PN, Stallwood CG, Nguyen L, et al. Cost-effectiveness of nonmelanoma skin cancer screening in Crohn's disease patients. Inflamm Bowel Dis 2013;19:2787-2795.

71. Loftus EV Jr, Crowson CS, Sandborn WJ, Tremaine WJ, O'Fallon WM, Melton LJ 3rd. Long-term fracture risk in patients with Crohn's disease: a population-based study in Olmsted County, Minnesota. Gastroenterology 2002;123:468-475.

72. Ananthakrishnan AN, McGinley EL, Binion DG, Saeian K. Fracture-associated hospitalizations in patients with inflammatory bowel disease. Dig Dis Sci 2011;56:176-182.

73. Bernstein CN, Leslie WD, Leboff MS. AGA technical review on osteoporosis in gastrointestinal diseases. Gastroenterology 2003;124:795-841.

74. American Gastroenterological Association medical position statement: guidelines on osteoporosis in gastrointestinal diseases. Gastroenterology 2003;124:791-794.

75. Lichtenstein GR, Abreu MT, Cohen R, Tremaine W; American Gastroenterological Association. American Gastroenterological Association Institute technical review on corticosteroids, immunomodulators, and infliximab in inflammatory bowel 
disease. Gastroenterology 2006;130:940-987.

76. Lichtenstein GR, Travis S, Danese S, et al. Budesonide MMX for the induction of remission of mild to moderate ulcerative colitis: A pooled safety analysis. J Crohns Colitis 2015;9:738-746.

77. D'Haens G, Verstraete A, Cheyns K, Aerden I, Bouillon R, Rutgeerts P. Bone turnover during short-term therapy with methylprednisolone or budesonide in Crohn's disease. Aliment Pharmacol Ther 1998;12:419-424.

78. Mittermaier C, Dejaco C, Waldhoer T, et al. Impact of depressive mood on relapse in patients with inflammatory bowel disease: a prospective 18-month follow-up study. Psychosom Med 2004;66:79-84.

79. Walker JR, Ediger JP, Graff LA, et al. The Manitoba IBD cohort study: a population-based study of the prevalence of lifetime and 12-month anxiety and mood disorders. Am J Gastroenterol 2008;103:1989-1997.

80. Long MD, Kappelman MD, Martin CF, Chen W, Anton K, Sandler RS. Risk factors for depression in the elderly inflammatory bowel disease population. J Crohns Colitis 2014;8:113-119.

81. Reynolds K, Pietrzak RH, El-Gabalawy R, Mackenzie CS, Sareen J. Prevalence of psychiatric disorders in U.S. older adults: findings from a nationally representative survey. World Psychiatry 2015; 14:74-81.

82. Guthrie E, Jackson J, Shaffer J, Thompson D, Tomenson B, Creed F. Psychological disorder and severity of inflammatory bowel disease predict health-related quality of life in ulcerative colitis and Crohn's disease. Am J Gastroenterol 2002;97:1994-1999.

83. Van Assche G, Dignass A, Reinisch W, et al; European Crohn's and Colitis Organisation (ECCO). The second European evidencebased Consensus on the diagnosis and management of Crohn's disease: Special situations. J Crohns Colitis 2010;4:63-101.

84. Miehsler W, Weichselberger M, Offerlbauer-Ernst A, et al. Assessing the demand for psychological care in chronic diseases: development and validation of a questionnaire based on the example of inflammatory bowel disease. Inflamm Bowel Dis 2004; 10:637-645.

85. Akerkar GA, Peppercorn MA, Hamel MB, Parker RA. Corticosteroid-associated complications in elderly Crohn's disease patients. Am J Gastroenterol 1997;92:461-464.

86. Ananthakrishnan AN, McGinley EL, Binion DG. Inflammatory bowel disease in the elderly is associated with worse outcomes: a national study of hospitalizations. Inflamm Bowel Dis 2009; 15:182-189.

87. Juneja M, Baidoo L, Schwartz MB, et al. Geriatric inflammatory bowel disease: phenotypic presentation, treatment patterns, nutritional status, outcomes, and comorbidity. Dig Dis Sci 2012;57:2408-2415.

88. Van Gossum A, Cabre E, Hébuterne X, et al; ESPEN. ESPEN Guidelines on Parenteral Nutrition: gastroenterology. Clin Nutr 2009;28:415-427.

89. Burns DM. Cigarette smoking among the elderly: disease consequences and the benefits of cessation. Am J Health Promot 2000;14:357-361.

90. Lakatos PL, Vegh Z, Lovasz BD, et al. Is current smoking still an important environmental factor in inflammatory bowel diseases? Results from a population-based incident cohort. Inflamm Bowel Dis 2013;19:1010-1017.

91. Lunney PC, Kariyawasam VC, Wang RR, et al. Smoking prevalence and its influence on disease course and surgery in Crohn's disease and ulcerative colitis. Aliment Pharmacol Ther 2015;42:61-70.

92. Parkes GC, Whelan K, Lindsay JO. Smoking in inflammatory bowel disease: impact on disease course and insights into the aetiology of its effect. J Crohns Colitis 2014;8:717-725.
93. Ducharme-Benard S, Cote-Daigneault J, Lemoyne M, et al. Patients with inflammatory bowel disease are unaware of the impact of smoking on their disease. J Clin Gastroenterol 2015;50:490-497.

94. Coward S, Heitman SJ, Clement F, et al. Funding a smoking cessation program for Crohn's disease: an economic evaluation. Am J Gastroenterol 2015;110:368-377.

95. Kappelman MD, Horvath-Puho E, Sandler RS, et al. Thromboembolic risk among Danish children and adults with inflammatory bowel diseases: a population-based nationwide study. Gut 2011;60:937-943.

96. Nguyen GC, Sam J. Rising prevalence of venous thromboembolism and its impact on mortality among hospitalized inflammatory bowel disease patients. Am J Gastroenterol 2008;103:2272-2280.

97. Grainge MJ, West J, Card TR. Venous thromboembolism during active disease and remission in inflammatory bowel disease: a cohort study. Lancet 2010;375:657-663.

98. Nguyen GC, Bernstein CN, Bitton A, et al. Consensus statements on the risk, prevention, and treatment of venous thromboembolism in inflammatory bowel disease: Canadian Association of Gastroenterology. Gastroenterology 2014;146:835-848.

99. Ananthakrishnan AN, Cagan A, Gainer VS, et al. Thromboprophylaxis is associated with reduced posthospitalization venous thromboembolic events in patients with inflammatory bowel diseases. Clin Gastroenterol Hepatol 2014;12:1905-1910.

100. Papa A, Papa V, Marzo M, et al. Prevention and treatment of venous thromboembolism in patients with IBD: a trail still climbing. Inflamm Bowel Dis 2015;21:1204-1213.

101. Calvo P, Pablo L. Managing IBD outside the gut: ocular manifestations. Dig Dis 2013;31:229-232.

102. Yilmaz S, Aydemir E, Maden A, Unsal B. The prevalence of ocular involvement in patients with inflammatory bowel disease. Int $J$ Colorectal Dis 2007;22:1027-1030.

103. Bernstein CN, Blanchard JF, Rawsthorne P, Yu N. The prevalence of extraintestinal diseases in inflammatory bowel disease: a population-based study. Am J Gastroenterol 2001;96:1116-1122.

104. Singhal S, Dian D, Keshavarzian A, Fogg L, Fields JZ, Farhadi A. The role of oral hygiene in inflammatory bowel disease. Dig Dis Sci 2011;56:170-175.

105. Vavricka SR, Manser CN, Hediger S, et al. Periodontitis and gingivitis in inflammatory bowel disease: a case-control study. Inflamm Bowel Dis 2013;19:2768-2777.

106. Katsanos KH, Roda G, McBride RB, Cohen B, Colombel JF. Increased risk of oral cancer in patients with inflammatory bowel diseases. Clin Gastroenterol Hepatol 2016;14:413-420.

107. Parian A, Ha CY. Older age and steroid use are associated with increasing polypharmacy and potential medication interactions among patients with inflammatory bowel disease. Inflamm Bowel Dis 2015;21:1392-1400.

108. Cross RK, Wilson KT, Binion DG. Polypharmacy and Crohn's disease. Aliment Pharmacol Ther 2005;21:1211-1216.

109. Klotz U. Pharmacokinetics and drug metabolism in the elderly. Drug Metab Rev 2009;41:67-76.

110. Lobatón T, Ferrante M, Rutgeerts P, Ballet V, Van Assche G, Vermeire S. Efficacy and safety of anti-TNF therapy in elderly patients with inflammatory bowel disease. Aliment Pharmacol Ther 2015;42:441-451.

111. Desai A, Zator ZA, de Silva P, et al. Older age is associated with higher rate of discontinuation of anti-TNF therapy in patients with inflammatory bowel disease. Inflamm Bowel Dis 2013;19:309-315. 